\title{
Cellobiose/mannitol sugar permeability test complements biopsy histopathology in clinical investigation of the jejunum
}

\author{
S STROBEL, W G BRYDON, AND ANNE FERGUSON \\ From the Gastro-Intestinal Unit, University of Edinburgh and Western General Hospital, Edinburgh, \\ Scotland
}

SUMMARY Intestinal permeability to probe molecules has been shown to correlate closely with the presence or absence of villous atrophy in a jejunal biopsy. The purpose of this study was to establish if there exist groups of patients with functional derangement of intestinal permeability but normal histopathology of the small bowel mucosa. In 135 patients a cellobiose/mannitol permeability test was performed at the same time as jejunal biopsy. Diagnosis included coeliac disease, Crohn's disease, irritable bowel syndrome, idiopathic diarrhoea, self diagnosed food allergy, atopic eczema and postinfectious malabsorption. The value of the cellobiose/mannitol test in identifying patients with abnormal jejunal biopsy histopathology was confirmed. The permeability test was abnormal in all 28 patients with partial or subtotal villous atrophy, and also in all 10 in whom there was a high intraepithelial lymphocyte count despite normal villi and crypts. Functional abnormality of the small intestine has not previously been reported in patients with this jejunal biopsy abnormality. Abnormalities of permeability were also found in patients with idiopathic diarrhoea, folate deficiency, postinfectious or traveller's diarrhoea, small bowel Crohn's disease, and atopic eczema. These results show that sugar permeability tests have more potential in clinical investigation than merely serving as screening tests before jejunal biopsy. There are groups of patients without morphological changes in the small bowel in whom intestinal permeability is abnormal.

Several abnormal features of transepithelial transport occur in diseases of the small intestine associated with villous atrophy. These include impairment in active absorption of various nutrients, reduction in the passive penetration of the epithelium by small probe molecules and an increase in the permeability to larger molecules of molecular radius greater than $0.5 \mathrm{~nm}$. Such observations form the theoretical basis for several recently described tests of intestinal permeability, ${ }^{1-3}$ which measure the absorption or penetration of large and small probe molecules. The ratio of permeability for large versus small probes is increased in patients with coeliac disease $\mathrm{s}^{3-5}$ and it has been suggested that an intestinal permeability test will provide one method for screening patients who should be submitted to jejunal biopsy. ${ }^{6}$

Address for correspondence: Dr Stephan Strobel, Gastro-Intestinal Unit, Western General Hospital, Crewe Road, Edinburgh EH4 2XU, Scotland. Received for publication 15 February 1984
In the initial clinical assessments of these permeability tests, several patients with non-coeliac gastrointestinal disease ${ }^{67}$ or with atopic eczema ${ }^{8}$ have been described, in whom permeability ratios are abnormal. Thus there may exist groups of patients with functional derangement of intestinal permeability, in which the bowel is 'leaky' to large probes, even though histopathology is normal. Clearly, this could provide an entirely new approach to investigation of disorders of the jejunum although it will remain essential to interpret the results of such permeability tests in the knowledge of intestinal histopathology. We have performed, simultaneously, jejunal biopsy and a cellobiose/ mannitol sugar permeability test in order to determine if indeed these tests are complementary. One hundred and thirty five patients were investigated, all of whom were undergoing investigation of diarrhoeal disease, malabsorption or possible food allergy. The results show not only that the sugar permeability test will predict all 
patients with abnormal jejunal histopathology, but also that there exist a group of distinct clinical and pathological entities, where sugar permeability is abnormal despite unequivocally normal jejunal biopsy histopathology.

\section{Methods}

PATIENTS AND VOLUNTEERS

Fifteen normal volunteers who had not had jejunal biopsy (healthy laboratory and medical staff) age range 21-42 years, were used to establish a provisional normal range for the test. As the test. solution contained lactose, a further five doctors, all clinically lactose malabsorbers (assessed by the breath hydrogen test after a lactose load) also participated in the test.

\section{BIOPSIED PATIENTS}

Patients undergoing jejunal biopsy for conventional clinical indications - diarrhoea, suspected malabsorption, follow up of treated coeliac disease and possible food allergic disease - comprised the study group. There were 135 patients, an unselected sequential series of patients, whose ages ranged from 14-75 years. After the study had been completed, case notes were reviewed retrospectively and a final diagnosis made on the basis of all the clinical information including the result of the jejunal biopsy histopathology and disaccharidase assays but without knowledge of the result of the sugar permeability test. The final diagnoses are listed in Table 1.

\section{INVESTIGATIVE PROCEDURES}

The procedures were performed mainly in out patients, who attend a clinical investigation suite

\section{Table 1 Diagnoses in volunteers and patients}

\begin{tabular}{|c|c|c|}
\hline \multicolumn{3}{|c|}{ Non-biopsied } \\
\hline $\mathbf{N}$ & - Normal volunteers & 15 \\
\hline $\mathbf{L}$ & - Lactase deficient clinical staff & 5 \\
\hline \multicolumn{3}{|c|}{ Biopsied } \\
\hline $\mathbf{N}$ & $\begin{array}{l}\text { - Normal (volunteers and healthy relatives of } \\
\text { coeliacs) }\end{array}$ & 9 \\
\hline IBS & - Irritable bowel syndrome & 15 \\
\hline ID & - Idiopathic diarrhoea & 10 \\
\hline 'FA' & $\begin{array}{l}\text { - Self diagnosed food allergy - not substantiated on } \\
\text { clinical investigation }\end{array}$ & 9 \\
\hline AE & - Atopic eczema & 13 \\
\hline $\mathrm{Cr}$ & - Small intestinal Crohn's disease & 7 \\
\hline UC & - Ulcerative colitis & 3 \\
\hline I & - Postinfectious diarrhoea (+ bacterial colonisation) & 7 \\
\hline $\mathbf{H}$ & - Folate deficiency (presumed nutritional) & 5 \\
\hline $\mathbf{M}$ & - Miscellaneous gastrointestinal disorders & 17 \\
\hline ND & - Coeliac disease (normal diet) & 13 \\
\hline GFD & - Gluten free diet prescribed & 27 \\
\hline
\end{tabular}

staffed by nurses. After an overnight fast the patient reported at about $8 \mathrm{am}$, emptied his bladder and then swallowed a prepared Watson peroral biopsy capsule, with a few sips of water. Fifteen milligrams metochlopromide was given orally. Five minutes later the patient started to drink the sugar test solution, and this was consumed within five minutes. The position of the biopsy capsule was monitored by screening and when the capsule was beyond the ligament of Treitz, a biopsy was taken in the usual way and the capsule withdrawn. Patients fasted for a total of five hours after ingestion of the sugar test solution, with the exception of water, tea or coffee without milk or sugar which were allowed after $2 \frac{1}{2}$ hours. All urine passed within five hours of the sugar drink was collected, the volume measured and an aliquot stored at $-20^{\circ} \mathrm{C}$. The composition of the sugar test solution was as follows: $2 \mathrm{~g}$ mannitol, $5 \mathrm{~g}$ cellobiose, $20 \mathrm{~g}$ lactose, $20 \mathrm{~g}$ sucrose made up to 150 $\mathrm{ml}$ with tap water to give an osmolality of approximately 1500 mosm. ${ }^{3}$

The jejunal biopsy was examined with a dissecting microscope and processed for conventional histopathological diagnosis. Subsequently all slides were coded and reviewed. The histology was classified as either unequivocally abnormal with partial or subtotal villous atrophy; essentially normal with normal villus and crypt architecture but with a high intraepithelial lymphocyte count (>40 lymphocytes/ 100 epithelial cells); ${ }^{9}$ and completely normal, with normal villus crypt architecture and normal intraepithelial lymphocyte count. Disaccharidases lactase, sucrase, trehalase and maltase were assayed by Dahlqvist's method. ${ }^{10}$

\section{MANNITOL AND CELLOBIOSE ASSAYS \\ Mannitol}

Mannitol in urine was measured by the method of Corcoran and Page, ${ }^{11}$ and is oxidised to formaldehyde by periodic acid. The formaldehyde reacts with chromotropic acid to form a purple complex which is measured at $570 \mathrm{~nm}$ absorbance.

\section{Cellobiose}

A new method, suitable for routine clinical diagnostic laboratories was developed - this avoided a need for quantitative paper chromatography. Cellobiose reacted with $\beta$-glucosidase to yield two molecules of glucose/cellobiose molecule. D-glucose was then measured using the hexokinase procedure with NADPH generation measured at $340 \mathrm{~nm}$ (see appendix). The hyperosmolar sugar solution used for this procedure was similar to several previously published studies and contained $20 \mathrm{~g}$ lactose. The Sigma B-glucosidase used in the measurement of cellobiose had lactose hydrolytic activity. In order to 
Table 2 Urinary recoveries of cellobiose and mannitol (total and \% ingested dose 15 hours) in normals and patients

\begin{tabular}{|c|c|c|c|c|c|}
\hline Disease & Mannitol/5 $h x \pm S D(g)$ & Cellobiose/5 $h x \pm S D(g)$ & Mannitol $\% \bar{x} \pm S D$ & Cellobiose \% $\bar{x} \pm S D$ & Not \\
\hline Normal volunteers & $\begin{array}{c}0.47 \pm 0 \cdot 12 \\
(0.39 \pm 0 \cdot 17)^{*}\end{array}$ & $\begin{array}{c}0.027 \pm 0.008 \\
(0.016 \pm 0.01)\end{array}$ & $\begin{array}{c}23 \cdot 3 \pm 5 \cdot 0 \\
(19 \cdot 6 \pm 8 \cdot 3)\end{array}$ & $\begin{array}{c}0.54 \pm 0.16 \\
(0.32 \pm 0 \cdot 20)\end{array}$ & 15 \\
\hline Irritable bowel syndrome & $0.42 \pm 0.012$ & $0.026 \pm 0.012$ & $21 \cdot 0 \pm 5 \cdot 8$ & $0.51 \pm 0.25$ & 11 \\
\hline Eczema (with C/M ratio) & $0 \cdot 31 \pm 0 \cdot 12$ & $0.041 \pm 0.013$ & $15 \cdot 6 \pm 6 \cdot 2$ & $0.82 \pm 0.26$ & 4 \\
\hline Coeliac disease & $\begin{array}{c}0.25 \pm 0.11 \\
(0.17 \pm 0.13)\end{array}$ & $\begin{array}{c}0.064 \pm 0.045 \\
(0.048 \pm 0.031)\end{array}$ & $\begin{array}{c}12 \cdot 5 \pm 5 \cdot 5 \\
(8 \cdot 3 \pm 6 \cdot 3)\end{array}$ & $\begin{array}{c}1.27 \pm 0.9 \\
(0.96 \pm 0.61)\end{array}$ & 27 \\
\hline Folate deficiency & $0.23 \pm 0.08$ & $0.040 \pm 0.02$ & $11 \cdot 4 \pm 4 \cdot 2$ & $0.79 \pm 0.41$ & 5 \\
\hline
\end{tabular}

${ }^{*}$ Results obtained by quantitative paper chromatography shown in brackets. ${ }^{56}$

$\dagger$ Individuals per group.

establish whether absorbed lactose interfered with the cellobiose assay, five normal subjects undertook sugar permeability tests on two occasions at least two days apart. In one test the sugar solution contained $20 \mathrm{~g}$ lactose and $20 \mathrm{~g}$ sucrose and in the other $40 \mathrm{~g}$ sucrose was used as the hyperosmolar agent. In addition five lactase deficient subjects undertook the sugar permeability test using the $20 \mathrm{~g}$ lactose, $20 \mathrm{~g}$ sucrose containing solution.

\section{Expression of results}

For each of the two administered probe molecules, cellobiose and mannitol, the percentage urinary recovery was calculated. The final ratio of percentage recovery of cellobiose to percentage recovery of mannitol was calculated. (Table 2).

\section{Results}

There were no practical problems associated with the combination of peroral jejunal biopsy and the sugar permeability test. The test solution was well tolerated. Two of the five lactase deficient volunteers reported loose bowel motions six to eight hours after ingestion of the sugar solution.

\section{NORMAL RANGE}

Urinary mannitol excretion was found to be within the range of previously reported values; cellobiose recovery rates as measured with the enzymatic assay were comparable with those measured by paper chromatography. ${ }^{56}$ In the five subjects used to study the effects of lactose on the measured urinary cellobiose, the per cent excretion of cellobiose when the lactose containing solution was administered was $0 \cdot 60 \pm 0 \cdot 13 \%$; and when lactose was excluded from the solution, the mean percentage excretion cellobiose was $0 \cdot 57 \pm 0 \cdot 21 \%$. By using Wilcoxon's rank sum test for pairs no significant differences between these two groups of measurements were present. In the five lactase deficient subjects percent cellobiose excretion was $0 \cdot 47 \pm 0 \cdot 24 \%$ (mean \pm SD) with a range of $0 \cdot 17-0 \cdot 79 \%$. In the 15 non-biopsied volunteers cellobiose/mannitol (C/M) excretion ratio was in the range as shown in the Figure with a mean of 0.023 and standard deviation 0.007 , although it is noticeable that the distribution is skewed. Results in the five lactase deficient subjects ranged from $0 \cdot 01-0 \cdot 035$. We have taken the upper limit of normal for the test as the mean + two standard deviations of results in 15 normal volunteers, namely $0 \cdot 037$.

\section{RELATIONSHIP BETWEEN JEJUNAL BIOPSY \\ HISTOPATHOLOGY AND C/M RATIO}

Of 135 patients studied, 80 had a $\mathrm{C} / \mathrm{M}$ ratio within the normal range and 58 had ratios greater than $0 \cdot 037$. Correlation with histopathology is illustrated in Table 3. Not only did all 28 patients with partial or subtotal villous atrophy have an abnormal ratio, but so also did the 10 patients (including three treated coeliacs) with normal villi but high intraepithelial lymphocyte count.

\section{C/M RATIO IN DIAGNOSTIC GROUPS}

Of the patients in whom no significant jejunal disease was present, all but two had normal $\mathbf{C} / \mathbf{M}$ ratios. Thus these comprised the nine normal subjects, 15 patients with irritable bowel syndrome and nine with unsubstantiated, self-diagnosed food

Table 3

\begin{tabular}{lll}
\hline & $\begin{array}{l}\text { C/M } \\
\text { ratio } \\
\text { normal }\end{array}$ & $\begin{array}{l}\text { C/M ratio } \\
\text { high } \\
(>0.037)\end{array}$ \\
\hline Histopathology of jejunum & 80 & 17 \\
\hline Normal & - & 28 \\
Partial/subtotal villous atrophy & - & 10 \\
$\begin{array}{l}\text { Normal villi and crypts; high intraepithelial } \\
\text { lymphocyte count }\end{array}$ & - & \\
\hline
\end{tabular}


Figure Results of cellobiose/ mannitol excretion ratios in 20 volunteers and 135 patients. Abbreviations for clinical diagnostic categories are as listed in Table 1.

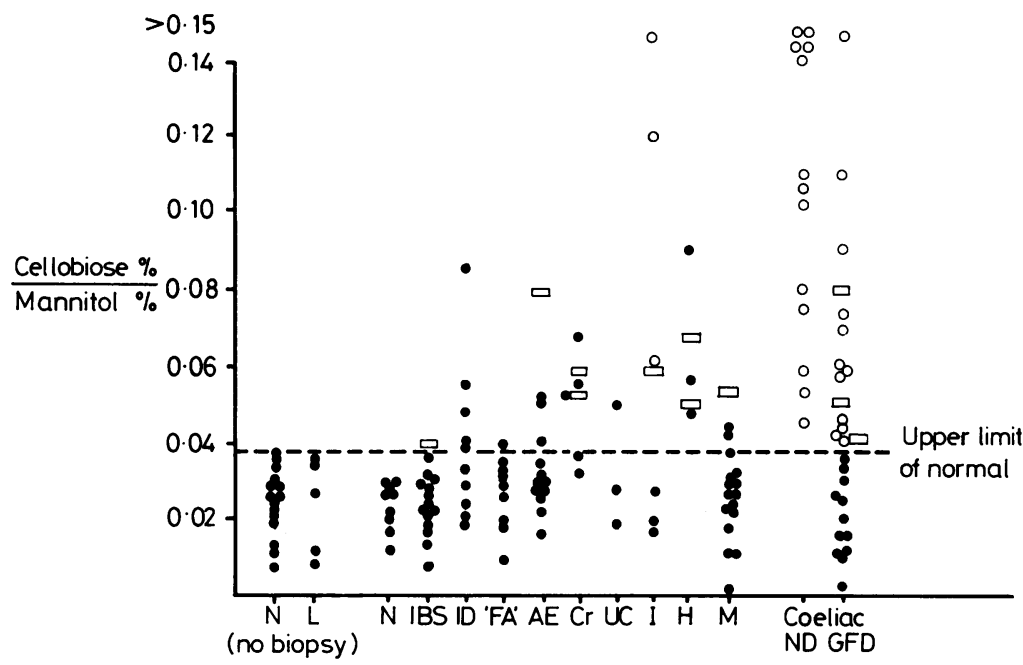

using an enzyme assay for cellobiose, it is possible to complete laboratory processing of a batch of tests within a single working day. Despite the use of a new method, values for cellobiose and mannitol excretion in normal subjects in this study are similar to those obtained in other centres, where cellobiose has been measured by chromatography. ${ }^{56}$ Theoretically, inclusion of lactose in the test solution might be considered inappropriate for there is the risk that absorbed lactose will interfere with the cellobiose assay. In a study carried out by Menzies, $0.09 \%$ of an ingested dose of $20 \mathrm{~g}$ lactose was excreted within 10 hours $(18 \pm 5 \mathrm{mg}$ lactose excreted, mean $\pm S D$ ). Over twice as much lactose was found to be excreted in subjects with hypolactasia. ${ }^{2}$ The experiments which we undertook to evaluate this aspect of the test have been reassuring in that they show no significant difference between the measured excretion of cellobiose in the normal subjects who performed the test with and without lactose in the hyperosmolar sugar solution. The difference between the two groups was only $0.03 \%$, equivalent to $1.5 \mathrm{mg}$ glucose or $3 \mathrm{mg}$ lactose. That is equivalent to $0.015 \%$ of the ingested dose, rather less than the $0.09 \%$ excretion reported by Menzies $^{2}$ who used paper chromatography, and studied lactose excretion over 10 hours. Furthermore, we have found no difference in per cent cellobiose excretion when normal lactase deficient subjects have been compared with other normal subjects.

Thus the results of the study indicated negligible interference from lactose in the enzymatic procedure for the measurement of cellobiose. A sugar solution containing both lactose and sucrose is 
distinctly more palatable than one containing sucrose alone. For these reasons, and in order to introduce as few variables as possible between our test and those previously reported in the literature, we have retained as the standard test solution, a drink which contains cellobiose, mannitol, sucrose, and lactose.

Although the mechanism by which these sugars penetrate the epithelium is still hypothetical, the existence of at least two different sets of pores has previously been postulated, ${ }^{12}(0.4 \mathrm{nM}$ diameter for mannitol, $0.52 \mathrm{nM}$ diameter for cellobiose). In patients with untreated coeliac disease and villous atrophy, reduction in mannitol recovery is thought to be because of a reduction of pores available for diffusion as a consequence of low surface area, whereas the increased permeability to larger molecules may be via epithelial discontinuities (altered tight junctions, cell extrusion zones). The present study confirms that abnormal results are obtained in all patients with partial or subtotal villus atrophy in a jejunal biopsy, not only in coeliac disease but also in patients with postinfectious malabsorption.

Intraepithelial lymphocytes (IEL) are normal constituents of the small intestinal epithelium. They can readily be counted in histological sections and, in man, normal values range from 10-40 IEL/100 villus epithelial cells. ${ }^{9}$ In animal experiments, increased intraepithelial lymphocyte counts occur predictably in intestinal mucosal cell mediated immune reactions. ${ }^{1314}$ Mucosal cell mediated immune reactions are also associated with crypt hyperplasia and villus atrophy. ${ }^{15}$ In some patients with coeliac disease, on treatment, or shortly after gluten reintroduction, high intraepithelial lymphocyte count in an otherwise normal jejunal biopsy may be the only abnormality (Ziegler and Ferguson unpublished). Ten of the patients in this present series had essentially normal jejunal biopsy morphology, with normal villi and crypts, normal enterocytes but a raised intraepithelial lymphocyte count, and all of these patients had an abnormal sugar permeability test whether or not the diagnosis was coeliac disease. This is the first report of any significant abnormality in small intestinal function, associated with a high intraepithelial lymphocyte count and tends to support the concept that a high intraepithelial lymphocyte count is a significantly abnormal finding and may in man, as well as in animals, reflect mucosal cell mediated immune reactions. Precisely how the abnormal permeability to probe sugars is related to the immunological abnormality remains to be established.

The simultaneous use of a permeability test and jejunal biopsy has allowed us to identify 17 individuals in whom cellobiose/mannitol permeability ratio was abnormal, despite an unequivocally normal jejunal biopsy (including normal intraepithelial lymphocyte count and disaccharidases). Diagnoses in these patients included idiopathic diarrhoea without malabsorption; severe atopic eczema; folate deficiency (presumed to be nutritional). Many patients with eczema have abnormal immune responses to foods. ${ }^{16}$ It is likely that local IgE mediated immune reactions to foods are the cause of the permeable intestine, but another explanation is that abnormal permeability to large molecules, sufficient to act as immunogens, is the primary cause of the food allergic state in some patients with atopic eczema.

Clearly, sugar permeability tests have a greater potential in clinical investigation than mere screening tests before jejunal biopsy. We have shown that a cellobiose/mannitol permeability test identifies several groups of patients with subtle nutritional or functional abnormalities. Because permeability tests appear to be abnormal in coeliac disease, Crohn's disease, intestinal infections as well as in food allergic states, investigations of patients with idiopathic diarrhoea or unexplained folate deficiency, seeking evidence of these conditions, may turn out to be fruitful. Finally, it will be important to determine whether increased permeability to large probe molecules is mirrored by increased absorption of food proteins, and whether such phenomena have any pathogenic role in inducing or maintaining harmful immune responses in the gastrointestinal mucosa.

\section{Appendix}

ENZYME ASSAY FOR CELLOBIOSE

The principle of the method is as follows. One cellobiose molecule reacts with $\beta$-glucosidase (Sigma G 8625) to yield two molecules of glucose. D-glucose is then measured using the hexokinase procedure with NADPH generation measured at $340 \mathrm{nM}$.

\section{REAGENTS}

$\beta$-glucosidase was obtained from Sigma Chemical Company, Dorset, UK. The $\beta$-glucosidase reagent contained $35 \mathrm{mg} \beta$-glucosidase per $\mathrm{ml}$ of acetate buffer $(0 \cdot 1 \mathrm{M}$ pH $5 \cdot 0)$. The reagent was prepared freshly before use and was centrifuged at $1600 \mathrm{~g}$ for 10 minutes at room temperature. The glucose assay kit was obtained from Sigma Chemical Company, Dorset, UK (Glucose No. 15-UV). 


\section{Method}

The following were incubated at $37^{\circ} \mathrm{C}$ with $0.2 \mathrm{ml}$ $\beta$-glucosidase reagent: $0.2 \mathrm{ml}$ water (reagent blank, B1), $0.2 \mathrm{ml}$ standard (S), and $0.2 \mathrm{ml}$ filtered urine (U).

The following were incubated at $37^{\circ} \mathrm{C}$ with $0.2 \mathrm{ml}$ acetate buffer $(0 \cdot 1 \mathrm{M}, \mathrm{pH} \mathrm{5.0)}, 0.2 \mathrm{ml}$ filtered urine

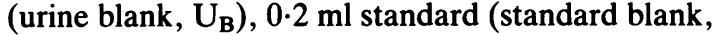
$\mathrm{S}_{\mathrm{B}}$ ). After two hours, the incubation mixtures were centrifuged for 10 minutes at $1600 \mathrm{~g}$, and $50 \mu \mathrm{l}$ supernatant was added to $1.2 \mathrm{ml}$ assay reagent; $50 \mu \mathrm{l}$ water was added to $1.2 \mathrm{ml}$ assay reagent. (Reagent Blank, $\mathrm{B}_{2}$ ).

After five minutes at room temperature, absorption of the solutions were read at $340 \mathrm{nM}$ on a Pye-Unicam SP 30 UV spectrophotometer with a flow cell attachment. The change in optical density (OD) for a standard containing $1 \mathrm{mg} / \mathrm{ml}$ cellobiose is about 0.6 absorbance units.

Calculation:

$\% 5 \mathrm{~h}$ cellobiose excretion ( $5 \mathrm{~g}$ dose administered)

$$
=\frac{\Delta \mathrm{OD}\left(\mathrm{U}-\mathrm{U}_{\mathrm{B}}\right)-\Delta \mathrm{OD}\left(\mathrm{B}_{1}-\mathrm{B}_{2}\right)}{\Delta \mathrm{OD}\left(\mathrm{S}-\mathrm{S}_{\mathrm{B}}\right)-\Delta \mathrm{OD}\left(\mathrm{B}_{1}-\mathrm{B}_{2}\right)} \times \frac{5 \mathrm{~h} \mathrm{vol}(\mathrm{ml})}{50}
$$

\section{COMMENTS}

Experiments in which cellobiose was added to urine and subsequently assayed, showed that the measured cellobiose was $96-108 \%$ of the amount added. The reproducibility of the overall technique, for calculation of cellobiose/mannitol ratio was $7.5 \%$ within batches, and $10.6 \%$ between batches. In areas where there is a high incidence of lactase deficiency, sucrose should be used as sole hyperosmolar agent to avoid abdominal discomfort.

We are grateful to all of those who participated in this study, to the clinical investigation nurses of the Gastro-Intestinal Unit, and to the consultants in the Gastro-Intestinal Unit who have allowed us to study patients in their care. We thank Mrs Doreen Orr for preparation of the manuscript. This work is supported by grants from the Lothian Health Board, the Coeliac Trust and the Scottish Home and Health Department. Dr Stephan Strobel is in receipt of a grant from the Deutsche Forschungsgemeinschaft (DFG Str 210/1).

\section{References}

1 Fordtran IS, Rector FC, Locklear TW, Ewton MF. Water and solute movement in the small intestine of patients with sprue. J Clin Invest 1967; 46: 287-98.

2 Menzies IS. Absorption of intact oligosaccharides in health and disease. Biochem Soc Trans 1974; 2: 1042-7.

3 Cobden I, Dickinson RJ, Rothwell J, Axon ATR. Intestinal permeability assessed by excretion ratios of two molecules: results in coeliac disease. $\mathrm{Br} \mathrm{Med} \mathrm{J}$ 1978; 2: 1060.

4 Menzies IS, Pounder R, Heyer S et al. Abnormal intestinal permeability to sugars in villus atrophy. Lancet 1979; 2: 1107-9.

5 Hamilton I, Cobden I, Rothwell J, Axon ATR. Intestinal permeability in coeliac disease: the response to gluten withdrawal and single dose gluten challenge. Gut 1982; 23: 202-10.

6 Cobden I, Rothwell J, Axon ATR. Intestinal permeability and screening tests for coeliac disease. Gut 1980; 21: 512-8.

7 Pearson AD, Eastham EJ, Laker MF, Craft AW, Nelson $R$. Intestinal permeability in children with Crohn's disease and coeliac disease. Br Med J 1982; 285: $20-1$.

8 Jackson PG, Lessof MH, Baker RWR Ferrett I, MacDonald DM. Intestinal permeability in patients with eczema and food allergy. Lancet 1981; 1: 285-6.

9 Ferguson A. Intraepithelial lymphocytes of the small intestine. Gut 1977; 18: 921-37.

10 Dahlqvist A. Method for assay of intestinal disaccharidases. Anal Biochem 1964; 7: 18-25.

11 Corcoran AC, Page IH. A method for the determination of mannitol in plasma and urine. Biol Chem 1947; 170: 165-71.

12 Frömter E, Diamond J. Route of passive ion permeation in epithelia. Nature New Biol 1972; 235: 9-13.

13 Mowat AMcI, Ferguson A. Hypersensitivity reactions in the small intestine. 5 Induction of cell mediated immunity to a dietary antigen. Clin Exp Immunol 1981; 43: 574-82.

14 Mowat AMcI, Ferguson A. Intraepithelial lymphocyte count and crypt hyperplasia measure the mucosal component of the graft-versus-host reaction in mouse small intestine. Gastroenterology 1982; 83: 417-23.

15 MacDonald TT, Ferguson A. Hypersensitivity reactions in the small intestine. 2 Effects of allograft rejection on mucosal architecture and lymphoid cell infiltrate. Gut 1976; 17: 81-91.

16 Barnetson RStC, Merrett TG, Ferguson A. Studies on hyperimmunoglobulinaemia $E$ in atopic diseases with particular reference to food allergens. Clin Exp Immunol 1981; 46: 54-60. 